\title{
Human Tumor Gene Index
}

National Cancer Institute

\section{Source}

National Cancer Institute. Human Tumor Gene Index. NCI Thesaurus. Code C15949.

Catalog of genes expressed in cells at various stages of tumor development. hGTI is part of CGAP. (Bypass Budget) 